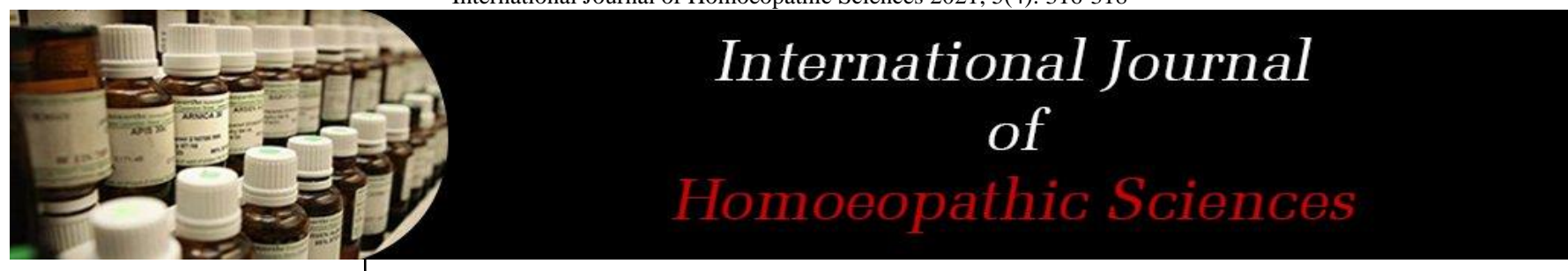

E-ISSN: $2616-4493$ P-ISSN: 2616-4485 www.homoeopathicjournal.com IJHS 2021; 5(4): 316-318

Received: 19-08-2021

Accepted: 21-09-2021

Dr. Bed Prakash Gond Lecturer, Department of Community Medicine, Netai

Charan Chakravarty

Homoeopathic Medical College \& Hospital, (WBUHS), Howrah, West Bengal, India
Corresponding Author: Dr. Bed Prakash Gond Lecturer, Department of Community Medicine, Netai Charan Chakravarty Homoeopathic Medical College \& Hospital, (WBUHS), Howrah, West Bengal, India

\section{The importance of causation in homoeopathy}

\section{Dr. Bed Prakash Gond}

DOI: https://doi.org/10.33545/26164485.2021.v5.i4e.491

\section{Abstract}

Generally, in our daily practice we deal with the prescription on the basis of Causation. This kind of prescription is strongly done by a number of cases successfully treated so far, we should not blindly considering the causation. It should be noted that, in some cases, the causation could either be a coincidence or a misconception. Hence always weigh its credibility before you consider.

Keywords: causation, cause, homoeopathy, tolle causam, prima causa morbi, miasma

\section{Introduction}

Among various systems of medicine, Homoeopathy gives great importance to causation. Causation is one of the segments of symptoms, which when strong and veritable, is of much benefit in the remedial diagnosis, and so far we have come across several successful cures made by remedies selected on this basis.

In the field of medicine, the word "Cause" has been used since ages. Physicians knew that there can't be diseases without a cause. Among the physicians of orthodox system, the concept of "Tolle causam" (remove the cause) was prevalent. The old school, without paying dew importance to the symptoms of patient, considers the material causes as the primary cause of the disease (Prima Causa Morbi). These old schools adherents believed that the bacteria, viruses and the material creations of the diseased persons are the real cause of the diseases. They considered that removal of these material causes will remove the disease. But this is a foolish assumption. These material causes are the proximate and not the distal cause of the diseases.

Master Hahnemann confidently asserts that the "Cause" of diseases is the miasms. The dynamic derangement of the vital force by the miasms only causes the diseases. Even the acute miasm cannot affect a person unless he is already dynamically infected by the psoric miasm, which is the original cause of all the diseases.

Another expression of "Cause" in homoeopathy is causation, which are the factors responsible for a symptom produced in an individual patient. We know that causation, location, sensation, modalities, and concomitants are the components of a symptom. It is not mandatory to have all these components in a given symptom. The causations and modalities mentioned in the Materia medica and also in the repertories are the exciting causes that can result in the production of symptoms in a sensitive or susceptible individual. Our body is sensitive to the external world and reacts to any stimuli on the basis of individual sensitivity and susceptibility developed as a result of the miasmatic background. Some external influences can activate the latent psora and the signs and symptoms are manifested externally. Here, the indicated medicine similar to the signs and symptoms of the patient can be given to achieve a cure.

\section{Sources of causation}

The following are the sources of causation.

1) Details told by the patient

2) Information from the bystanders

3) Understood by the doctor by logical thinking

4) Perceived by clinical examination

5) Impressions from the lab investigations

6) from a second opinion by another doctor 


\section{Stalwarts on Causation}

Master Hahnemann: In the Medicine of Experience, he offered several insights into the subject of causation. Later, after several years' practice he found out the concept of Miasms as the real cause of diseases. As per Hahnemann, Miasms are diseases having "one and the same cause". He was the first to postulate a complete theory of susceptibility, infection and how they affect our immunity. He understood the fact that miasmic infectious diseases are the basis of all diseases. He also identified the non-miasmatic diseases that can cause prolonged sickness as a result of several internal as well as external factors. If these maintaining causes are removed, the recovery is possible. In aphorism number 73 , Hahnemann tells about the acute diseases that affect individually as a result of exposure to injurious influences. Excess or insufficient supply of food, any sort of physical impressions, irritations, emotions etc can act as exciting causes. He says that these external factors actually cause the explosion of the latent psora, which was dormant initially.

Dr. Boenninghausen: He proposed the concept of complete symptom and introduced the various components of a symptom such as location, sensation, modalities, and concomitants. In order to give a complete image of a disease Boenninghausen introduced different factors related with a symptom such as Quis, quid, ubi, quibis auxillus, cur, quomodo, quando. In which Cur means the cause of the disease. As per Boenninghausen, causes of diseases can be divided in to internal and external causes. The internal causes refer to general natural disposition (proximate cause) and idiosyncrasy. The external causes are also termed as occasional causes. He emphasized the importance of anamnesis of the case and prescribing on the basis of circumstances or factors that caused the symptoms.

C M Boger: He introduced the Doctrine of causation into Homoeopathy and gave due importance to causation, time and general modalities and according to him this approach is more practical and proved. Boger proposed that, causation and time factors are more definite and reliable in cases as well as in medicines. As per Boger, cause could be miasmatic cause and exciting cause. In his synoptic key, he emphasizes that "while taking the case we should first try to elicit the evident cause and course of sickness and all which now to interfere with the patients comfort". Even though there is no separate section on causation in his repertory, the subsection Aggravation also includes the factors that excite or bring on the symptoms.

O E Boericke: In his repertory, each rubric, when extensive in scope, is presented in the order of cause, type, location, and character of pain, concomitants and modalities. Since the cause is given separately, it is useful for quick prescription.

J H Clark: In his clinical repertory, there are five main chapters in which the second one is Repertory of causation.

J C Burnet: He gave much importance to prescription on the basis of pathology. Hence his way of approach can be followed for cases that can be explained in terms of pathological causes.

\section{Repertories on Causation}

In other repertories like Kent's Repertory, Synthesis etc. causation is scattered.

\section{Causations mentioned in Boericke repertory}

1) Ailments from mental \& emotional causes: Anger, fright, grief, sorrow, jealousy, joy, vexation, nostalgia, mortification, discords, mental work, sedentary life, luxury, hysteria, tension, thinking, hastiness, hurry, worry, emotional excitement, loss of social position, insults, away from home, misdeeds of others, rape, disappointed love, hypochondriacs etc.

2) Ailments from history: History of diseases like gonorrhoea, syphilis, diphtheria, malaria, scarlet fever, influenza, pneumonia, eczema, intermittent fever, chickenpox, typhoid, zoster, whooping cough, measles etc.

3) Complaints related with age or life situation: Old age, climacteric, children, dentition, pregnancy, puberty, nursing, senile decay, lactation, after confinement, after marriage, puerperal, post partum etc.

4) Ailments due to organ involvement: Reflux symptoms from organs, gastric origin, cerebral origin, pelvic origin, cardiac, decayed teeth, renal, torpor of rectum, atony of rectum/bladder, prostrates hypertrophy etc.

5) Ailments due to individual sensitivity: Allergies, sensitiveness to noises, odours, odour of food, putrid odours, smoke, dust, flowers, noxious effluvia, visual disturbances, artificial light, glare, looking at moving objects, sea sickness, sight of food, bright objects, working under gas light, woollen clothes, hat etc.

6) Environmental Causes: Weather changes, rain, heat, sun, high altitude, wind, fog, dampness, open air, fanning, snow, lightning, fire, getting wet, sea bathing, washing clothes, draughts, ice, bathing, feet wet, autumn, moon, spring, sunstroke, mining, working in clay.

7) Complaints due to treatments: Medicines, vaccination, tonics, laxatives, vegetable medicines, sedatives, purgatives, anaesthesia, surgery, amputation, injection, tooth extraction, dental work, cauterization, curettage, local tar application, abuse of enemas, abdominal operation, lithotomy, abortion, spinal injection, and catheterization.

8) Complaints due to poisoning: Narcotics, stimulants, tobacco, alcohol, smoking, drug abuse, debauchery, mercury, arsenic, war gas, toxins, lead, copper, camphor, cantharis, chamomilla, colchicum, digitalis, ptomaine poisoning, quinine, occupational hazards.

9) Ailments from activity: Exertion, working, running, walking, night watching, dancing, singing, over lifting, eye strain, sewing, haircut, brushing, ironing, travelling (car, boat, rail), climbing mountain.

10) Complaints due to food and drinks: Indigestion, defective nutrition \&assimilation, overeating, fasting, hasty eating and drinking, bottle feeding, artificial food, breakfast, beer, tea, bread, butter, cabbage, cheese, cold/hot drinks, egg, fish, meat, fruits, melons, mushroom, onion, oyster, pastry, pork, potato, salt, sausage, soup, coffee, lemonade, spices, milk, fat, acids, decayed food, sour food, sweets, starchy food, strawberries, farinaceous food, seasoned food, vegetables, vinegar, vine, veal, impure water, flatulent food, cucumber, unripe fruits, indigestible items.

\section{Beware of Causations}

There is a trend among many of us to get prejudiced in the remedial diagnosis, when the prescription is given on the 
basis of causation. For example: Arnica for injury, Rhus Tox for physical exertion, Natrum Mur for grief. If we refer repertory, we can see that there are many drugs indicated for the above causations. Hence, if we follow the prejudiced way of prescription, we may miss some other drug that may also cover the same causation and may be much more similar to the whole case. However, the prescription on the basis of causation has helped us a lot and is still working for many cases; we should not be blind in considering the causation for a remedial diagnosis. In many of the cases, the causation could be a coincidence or a misconception. Sometimes the patient may tell that so and so factor is responsible for his ailments but may not be the real cause. Hence we should not give over importance to anything unless we confirm by asking about the repeated history of the same complaint after exposing to any particular stimuli. Or else, we will be misguided. Of course, confirmation of causation is not that easy and may not be possible in certain cases. However maximum care has to be taken while weighing each and every word told by the patient.

\section{Conclusion}

True that we have cured many cases on the basis of causation, even for cases failed to respond to a "wellselected remedy". But we should always try to confirm the causation and consider its intensity. We know that there are different ways to arrive at a group of similar drugs, but only one way to reach the similimum, i.e. the highest level of similarity with the qualitative totality of the case. Hence always consider the whole individual rather than considering one or two symptoms.

\section{References}

1. Dr. Hahnemann Samuel. The Chronic Disease, Low price edition series; B Jain Publishers Pvt. Ltd 2010.

2. Dudgeon RE. Organon of Medicine, $5^{\text {th }} \& 6^{\text {th }}$ Edition, Indian Books \& Periodical Publishers.

3. Allen JH. The Chronic Miasm, Bjain Publishers (P) LTD., reprint 2004.

4. Nagendra Babu G. Comprehensive Study of Organon, Bjain Publishers (P) LTD. 2009-2018.

5. Robert HA. the Principles of Art and Cure by Homoeopathy. New Delhi: B. Jain Publishers (P) Ltd; Reprint ed. 1997.

6. Sarkar BK. Organon of medicine. Delhi: Birla Publications Pvt. Ltd. 10th Edition, reprint 2009-2010.

7. Allen HC. Allen's Keynotes, Rearranged and Classified with Leading Remedies of the Materia Medica and Bowel Nosodes, 10 ${ }^{\text {th }}$ Edition, B. Jain Publishers Pvt. Ltd. 2005.

8. Burt William H. Characteristic Materia Medica, University of Michigan Library 2006.

9. Phatak SR. Concise Materia Medica of Hom. Remedies, B Jain Publishers Pvt. Ltd; Enlarged Edition 2003.

10. Boericke William. Homoeopathic Materia Medica \& Repertory, B Jain Publishers Pvt. Ltd. 2003.

11. Murphy ND. Robin, Lotus Materia Medica, B Jain Publishers Pvt. Ltd. $2^{\text {nd }}$ Edition 2004.

12. Clarke JH. A Clinical Repertory to the Dictionary of Materia Medica, B Jain Publishers Pvt. Ltd. 2016.

13. Boger CM. characteristics and repertories; B Jain Publishers Pvt. Ltd. 2016.

14. Dr. Choudhuri NM. A Study on Materia Medica.
Revised and augmented edition: 8th impression, 2011 2001.

15. Dr. Banerjea Subrata Kumar. Miasmatic Prescribing. Second Extended Edition. B Jain Publishers Pvt. Ltd. 2017. 